\title{
Determinants of stillbirths among women who gave birth at Hawassa university comprehensive specialized hospital, Hawassa, Sidama, Ethiopia 2019: a case-control study
}

\author{
Rekiku Fikre ${ }^{1 *}$ (D) Samuel Ejeta ${ }^{1 *}$, Taye Gari ${ }^{1}$ and Akalewold Alemayhu ${ }^{2}$
}

\begin{abstract}
Background: Globally over 2.6 million pregnancy ends with stillbirth annually. Despite this fact, only a few sherds of evidence were available about factors associated with stillbirth in Ethiopia. Therefore, the study aimed to spot factors related to stillbirth among women who gave birth at Hawassa University Comprehensive Specialized Hospital Hawassa, Sidama Ethiopia, 2019.

Methods: Facility-based unmatched case-control study was conducted at Hawassa University Comprehensive Specialized Hospital. Cases were selected using simple random sampling technique and controls were recruited to the study consecutively after every case selection with case to control ratio of 1 to 3 . Data were coded and entered into Epi-data version 3.1 and exported to SPSS version 24 for analysis.

Results: $\mathrm{A}$ total of 106 cases and 318 controls were included in the study. Number of antenatal care visit [AOR= $0.38,95 \% \mathrm{Cl}(0.15,0.95)]$, lack of partograph utilization $[\mathrm{AOR}=4.195 \% \mathrm{Cl}(2.04,10.5)]$, prolonged labor $[\mathrm{AOR}=6.5$, $95 \% \mathrm{Cl}(2.9,14.4)]$, obstructed labor $[\mathrm{AOR}=3.5,95 \% \mathrm{Cl}(1.5,9.4)]$, and congenital defect $[\mathrm{AOR}=9.7,95 \% \mathrm{Cl}(4.08$, 23.0)] were significantly associated with stillbirth.
\end{abstract}

Conclusion: Absence of partograph utilization, prolonged labor, obstructed labor, antepartum hemorrhage and congenital anomaly were found to have positive association with stillbirth.

Keywords: Still birth, Determinants, Case-control, Ethiopia

\footnotetext{
* Correspondence: frekiku@yahoo.com; samejeta09@gmail.com

${ }^{1}$ Mettu University, College of Health Science, P.O. Box 2156, Mettu, Ethiopia

Full list of author information is available at the end of the article
}

(c) The Author(s). 2021 Open Access This article is licensed under a Creative Commons Attribution 4.0 International License, which permits use, sharing, adaptation, distribution and reproduction in any medium or format, as long as you give appropriate credit to the original author(s) and the source, provide a link to the Creative Commons licence, and indicate if changes were made. The images or other third party material in this article are included in the article's Creative Commons licence, unless indicated otherwise in a credit line to the material. If material is not included in the article's Creative Commons licence and your intended use is not permitted by statutory regulation or exceeds the permitted use, you will need to obtain permission directly from the copyright holder. To view a copy of this licence, visit http://creativecommons.org/licenses/by/4.0/. The Creative Commons Public Domain Dedication waiver (http://creativecommons.org/publicdomain/zero/1.0/) applies to the data made available in this article, unless otherwise stated in a credit line to the data. 


\section{Background}

Stillbirth is one of the public health problems and defined as a fetus born with no sign of life at or after 28 completed weeks of gestation with a birth weight of $1000 \mathrm{~g}$ or more and a body length of $>35 \mathrm{~cm} \mathrm{[1-3].} \mathrm{It} \mathrm{is} \mathrm{an} \mathrm{indication} \mathrm{for}$ the quality of obstetric care, accessibility as well feasibility of the health care facility to access the service and as a result, it ensued due to the previous history of stillbirth, fetal factor, maternal factors, and poor service delivery associated delay to receive care [2-4].

Globally more than 2.6 million pregnancy ends with stillbirth per annum and the majority of them ensues in the middle and lower-income countries and 55\% of this occurs during the intrapartum period [2, 3, 5]. Sub-Saharan and southeast Asian countries account for the highest share of stillbirth, 20 to 40 per 1000 births respectively, which is 10-fold higher compared to developed regions. Evidence suggested that in Finland 2 per 1000 total births verses 40 per 1000 birth in Ni Pakistan, and 30per 1000 in Ethiopia, clearly proved the discrepancy and the standard of maternal care service [6,7]. Despite stillbirth accounts for huge percent of perinatal mortality, the focus to alleviating the problem is poor as evidence by no emphasis given in the sustainable development goals 2015 [5, 8-10]. The impact of Stillbirth is multi-dimensional. It causes psychological depression for women and it has also effect on the daily life of a family and health care provider [11-15].

Ethiopia showed a decline in maternal mortality by 50\% from 1990 to 2016 and neonatal mortality from 55 per 1000 to 28 per 1000 live births between 1990 to 2015 [10]. This progress was due to the expansion of health facilities, an increment of competent providers and improvement in technologies $[6,16]$.

Despite this fact, Ethiopia ranked 5th in stillbirth rate among the top ten developing countries with 30 per 1000 live births. Approximately over 97,000 still births occur annually and 258 stillbirths occur daily [6].

Therefore, understanding the causes of stillbirth will be important to get timely representative data and run with every newborn action plan targeted to reduce preventable stillbirth to lower than 12 per 1000 live births [6]. The region is one of the three regions with high burden stillbirth next to Oromia and Amhara region [17]. Therefore, this study aimed to investigate key predictors of stillbirth related to some socio-demographic, obstetrics, and medical, fetal and some of the health care factors.

\section{Methods}

\section{Study setting and period}

The study was conducted in Hawassa University comprehensive specialized Hospital Hawassa, Sidama,
Ethiopia from June 1, to December 30, 2019. The hospital was located in Sidama Regional State Hawassa city. Hawassa city is found $275 \mathrm{~km}$ away from Addis Ababa, the capital of Ethiopia. The hospital was established by the Federal government of Ethiopia in 2005. The hospital was the only teaching and referral hospital in Hawassa city. It has more than 300 beds and It serves for a catchment population of 10-12 million. The hospital gives complete health care delivery services for about 53,384 patients with 8 special departments. Moreover, it provides complete labor and delivery service for the patient visiting from different zones of the region and neighboring regions. Pediatric, obstetrics and gynecology department are the pioneer in the provision of specialized maternal and newborn care including obstetric intensive care unit. In this hospital obstetrics and gynecology department activities have been run with 8 gynecologists, 93 midwives, and with several other staff.

\section{Population}

The source population were all mothers who gave birth at Hawassa University Compressive Specialized Referral Hospital. Cases were all mothers who gave stillbirth at Hawassa University Compressive Specialized Hospital during the period June 1, 2016, to May 31, 2019. Controls were all mothers who gave live birth at Hawassa University Compressive Specialized Hospital during the period June 1, 2016, to May 31, 2019.

\section{Eligibility criteria}

Inclusion criteria for both cases and controls

\section{Case}

A mother who gave birth at Hawassa university comprehensive specialized hospital during the period June 1, 2016, to May 31, 2019, in maternity ward based on WHO (IDC-10) by a skilled health professional and who had confirmed stillbirth.

\section{Control}

A mother who gave birth at Hawassa university comprehensive specialized hospital during the period June 1, 2016, to May 31, 2019, in maternity ward based on WHO (IDC-10) by a skilled health professional and who had documented live birth.

\section{Sample size determination}

The Sample size for this study was determined considering factors which have statistically significant association with still birth from previously undertaken studies. Previous studies showed not attending antenatal care, antenatal risk, length of labor, and uterine rupture were factors having statistically significant 
association with stillbirth. Sample size was estimated by considering case exposed, percent of control exposed, and AOR for each variable. Among the factors used to estimate sample size, not attending antenatal care has given the maximum sample which is 424 (106 cases and 318 controls) below; later on not attending antenatal care is selected by considering maximum sample size (Welegebriel, Dadi et al. 2017) by considering the following assumptions sample size computed by Epi-info version 3.03.

- $95 \%$ confidence levels

- $80 \%$ power of study

- 1 to 3 cases to control ratio

- $\mathrm{AOR}=2.09$

- percent of control exposed $=19.9$

- percent case exposed $=34.2$

Therefore, the final sample size will be recruited in the study $=424$ (106 cases and 318 controls) sample size computation

\begin{tabular}{|c|c|c|c|c|c|c|c|}
\hline \multirow[t]{2}{*}{ Variables } & \multirow{2}{*}{$\begin{array}{l}\text { Percent } \\
\text { of case } \\
\text { exposed }\end{array}$} & \multirow{2}{*}{$\begin{array}{l}\text { Percent of } \\
\text { controls } \\
\text { exposed }\end{array}$} & \multirow{2}{*}{ AOR } & \multicolumn{4}{|c|}{ Sample size } \\
\hline & & & & Case & Control & Total & References \\
\hline $\begin{array}{l}\text { Uterine } \\
\text { rupture }\end{array}$ & 68 & 22.9 & 4.9 & 21 & 63 & 84 & $\begin{array}{l}\text { (Welegebriel, } \\
\text { Dadi et al. } \\
\text { 2017) [18] }\end{array}$ \\
\hline $\begin{array}{l}\text { Birth } \\
\text { weight }< \\
2.5 \mathrm{~kg}\end{array}$ & 17.3 & 7.1 & 2.8 & 98 & 294 & 392 & $\begin{array}{l}\text { (Bayou and } \\
\text { Berhan 2012) } \\
\text { [19] }\end{array}$ \\
\hline $\begin{array}{l}\text { Not } \\
\text { attending } \\
\text { ANC }\end{array}$ & 34.2 & 19.9 & 2.09 & 106 & 318 & 424 & $\begin{array}{l}\text { (Welegebriel, } \\
\text { Dadi et al. } \\
\text { 2017) [18] }\end{array}$ \\
\hline $\begin{array}{l}\text { Length } \\
\text { of labour> } \\
24 \mathrm{~h}\end{array}$ & 43.8 & 21.3 & 2.44 & 49 & 145 & 194 & $\begin{array}{l}\text { (Welegebriel, } \\
\text { Dadi et al. } \\
\text { 2017) [18] }\end{array}$ \\
\hline
\end{tabular}

\section{Sampling procedure}

Hawassa University Comprehensive Specialized Hospital was selected purposefully based on referral status. All mothers who gave birth at Hawassa University Comprehensive Specialized Hospital during the period June 1, 2016, to May 31, 2019, registered in the registration logbook was used source population. There was a total of 15,235 deliveries counted in the logbook over 3 years. From these 316 total stillbirths and 14,919 live births were identified.

The maternal chart that had incomplete documentation were excluded from the study. Finally, 106 cases and 318 controls were selected by using simple random sampling technique by considering the delivery registration book serial number as a sampling frame.

\section{Operational definition Stillbirth}

It is a fetus born dead after 28 weeks of gestational age with a birth weight of $>1000 \mathrm{~g}$ during the antepartum or intrapartum period (WHO, 2016).

\section{Data collection}

A pretested and structured checklist that was developed after relevant literature review for the problem under the study was used. The checklist was designed to obtain information that encompasses the main variable for some demographic, obstetrics, and medical complication as well as fetal and healthrelated factors. Four BSc midwife's data collectors and one MSc clinical midwifery supervisor were recruited for the data collection. Data collectors and supervisors identify cases and controls along with their respective chart numbers. All selected maternal charts were obtained through communicating with a responsible person of the hospital after a list of cases and controls given to them for trace.

Data collectors review maternal medical chart of case and control from prenatal history and obstetric history, intrapartum follow-up sheet, delivery summary, and laboratory and sonographic notes in the maternal chart were filled into the checklist.

\section{Data quality control}

Two-days training was given for data collectors and supervisors before data collection. Before the actual data collection begin checklist has been pre-tested on $5 \%$ of the total sample size at Yirgalem general Hospital. After pretesting questions were revised and adjusted. Data collectors were daily supervised by the supervisor and daily activities were reported to the principal investigator.

\section{Data analysis}

After data collection completed, a filled checklist has been checked for completeness, coded, cleansed then entered into Epi-data 3.1 version. Afterward, it was exported into the statistical package for social science software version 24 for analysis. Descriptive statistics; proportion and cross-tabulation were done to see characteristics of exposure variable between stillbirths and live birth. Variables in the bivariate logistic regression analysis with a $p$-value $<0.25$ were included in multivariate logistic regression analysis. Multi collinearity was diagnosed by using the variance inflation factor to see the correlation among independent variables. The Goodness of fit of the final model was checked using Hosmer and Lemeshow test of goodness of fit test. Finally, $p$-value, Adjusted Odds Ratio with $95 \% \mathrm{CI}$ was presented with narration and table 
form. Variables having a $p$-value $<0.05$ in multivariate logistic regression model were considered to be statistically significant predictors of still birth.

\section{Results}

\section{Sociodemographic characteristics}

A total of 106 cases and 318 controls women were included in the study. The mean age of the cases was 27.87 with $\mathrm{SD}+6.45$ and the mean age of the controls was 27.69 with $\mathrm{SD}+6.27$. Almost half $51(48.1 \%)$ of the cases and nearly half $158(47.7 \%)$ of controls were ranged in the age group of 21 to 25 years old age. In this study $56(52.8 \%)$ of the cases and $130(40.9 \%)$ of the controls were from a rural area. Regarding marital status, $101(95.3 \%)$ of the cases and 312(98.1\%) of the controls were married. However, the pregnancy status of the participant, 79 (74.5\%) of the case, and 237(74.5\%) of the controls were multigravida mother. (Table 1). Regarding types of stillbirth identified in this study among 106 of the cases $77(72.6 \%)$ was a fresh stillbirth, 22(20.8\%) was macerated stillbirth and 7(6.6\%) of stillbirth unclassified type of stillbirth (Fig. 1).

\section{Health care service-related characteristics}

The majority of the study participants $89(84.0 \%)$ of the cases and $264(83.0 \%)$ of the controls had antenatal care.

Table 1 Socio-demographic and reproductive characteristics of study Participants in Hawassa University Comprehensive Specialized Hospital, Hawassa, Sidama, 2019

\begin{tabular}{lllll}
\hline Variable & Category & $\begin{array}{l}\text { Cases } \\
\text { N (\%) }\end{array}$ & $\begin{array}{l}\text { Controls } \\
\text { N (\%) }\end{array}$ & P-value \\
\hline Maternal age at birth & $16-20$ & $17(16.0)$ & $54(17.0)$ & 0.460 \\
& $21-25$ & $51(48.1)$ & $158(49.7)$ & \\
& $26-30$ & $13(12.3)$ & $35(11)$ & \\
& $31-35$ & $14(13.2)$ & $40(12.6)$ & \\
Residence & $36-40$ & $11(10.4)$ & $31(9.7)$ & \\
Marital status & Urban & $50(47.2)$ & $188(59.1)$ & 0.032 \\
Gravidity & Rural & $56(52.8)$ & $130(40.9)$ & \\
& Not married & $5(4.7)$ & $6(1.9)$ & 0.012 \\
Parity & Married & $101(95.3)$ & $312(98.1)$ & \\
& primi gravida & $27(25.5)$ & $81(25.5)$ & 0.077 \\
& Multigravida & $79(74.5)$ & $237(74.5)$ & \\
Abortion & Primiparous & $54(50.9)$ & $173(54.4)$ & 0.325 \\
& Multiparous & $29(27.4)$ & $96(30.2)$ & \\
Previous Stillbirth & GMP & $23(21.7)$ & $49(15.4)$ & \\
& Yes & $32(30.2)$ & $59(18.6)$ & 0.012 \\
& No & $74(69.8)$ & $259(81.4)$ & \\
& No & $12(11.3)$ & $22(6.9)$ & 0.148 \\
Nes & $94(88.7)$ & $296(93.1)$ & \\
\hline
\end{tabular}

Note: $N$ Number while, (\%) Represents percent, MP Grand multiparous
More than two thirds, 68(64.2\%) of the cases and $98(30.8 \%)$ of the controls were referred from other health facilities. Regarding intrapartum labor monitoring, 86(81.1\%) of the cases and 298(93.7\%) of the controls partograph was utilized.

\section{Obstetrics and medical illness-related characteristics}

Regarding obstetrics complication majority, 92(86.8\%) of the cases and 194(61.0\%) of the controls had obstetrics complications during pregnancy and delivery. Concerning the onset of labor $66(62.3 \%)$ of the cases and $227(71.4 \%)$ of the controls labor started spontaneously, while $40(37.7 \%)$ of the cases and 91(28.6\%) of the controls were labor onset by induction. Nearly three-fourth, 73(68.9\%) of the cases and almost half, $156(49.1 \%)$ of the controls gave birth vaginally, while $33(31.1 \%)$ of the cases and $162(50.9 \%)$ of the controls were given birth by caesarian section. Almost more than one thirds $40(37.7 \%)$ of the cases and $27(8.5 \%)$ of the controls were given birth after $24 \mathrm{~h}$. Nearly half of the study participant $49(46.2 \%)$ of the cases and $88(27.2 \%)$ of the controls labor started at a health facility. Twenty-two (24.6\%) of the cases and $34(10.7 \%)$ of the controls had obstructed labor. Although, 7(6.6\%) of the cases and $21(6.6 \%)$ of the controls had oligohydramnios, while $4(3.8 \%)$ of the cases and $5(1.6 \%)$ of the control had polyhydramnios. Concerning medical illness $53(50.0 \%)$ of the cases and $139(43.0 \%)$ of controls have a diagnosis of medical complications (Table 2).

\section{Fetal related characteristics}

On the issue of fetal related characteristics, $68(64.2 \%)$ of the cases, and $94(29.6 \%)$ of the controls had fetal distress. However, $10(9.4 \%)$ of the cases and $9(2.8 \%)$ of the controls were have a diagnosis of cord prolapsed. The majority of the study participant, $51(48.1 \%)$ of the cases, and 195(61.3\%) of the controls were term fetuses. More than two thirds, 61(57.5\%) of the cases and $235(73.9 \%)$ of the controls had given normal birth weight fetus. About fetal presentation, $73(68.9 \%)$ of the cases and 203(63.8\%) of the controls were a cephalic presentation during labor and delivery. More than half, $59(55.7 \%)$ of the cases and $188(59.1 \%)$ of the controls gave birth to the female sex. Furthermore, about the fetal congenital anomalies $21(19.8 \%)$ of the cases and $16(5.0 \%)$ of the controls had birth defects (Table 3).

\section{Determinants of stillbirth among mother who gave birth} at Hawassa comprehensive specialized hospital

The odds of stillbirth is $62 \%$ less likely among mothers who had four antenatal care visits compared to mothers who had less than four antenatal care visit $[\mathrm{AOR}=0.38$ CI $(0.15,0.95)]$. However, the odds of women whose birth weren't followed up by partograph were 4 times 


\section{cases}

\section{$\square$ fresh stillbirth $\quad$ macerated stillbirth $\quad$ undoumented stillbirth}

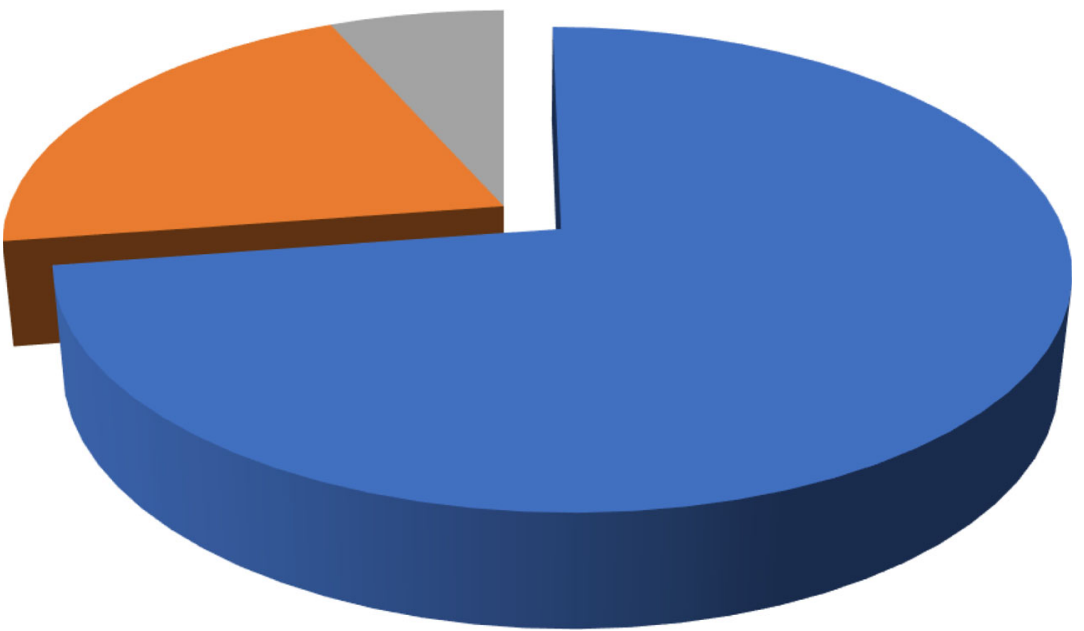

Fig. 1 Type of stillbirth among women who gave birth in Hawassa University comprehensive specialized Hospital Hawassa, sidama, Ethiopia 2019

higher risk of encountering stillbirth compared to labor monitored by partograph $[\mathrm{AOR}=4.1(2.04,10.5)]$. On the other hand, the odd of women who gave birth by cesarean delivery were $67 \%$ less likely to have stillbirth than mothers who gave birth through vaginal delivery $[\mathrm{AOR}=0.33 \mathrm{CI}(0.16,0.68)]$. The odds of a mother who had prolonged labor were 6 times more likely to have stillbirth $[\mathrm{AOR}=6.5 \mathrm{CI}(2.9,14.4)]$ compared to a mother who gave birth within $24 \mathrm{~h}$. Also, the odds of women who had a diagnosis of obstructed labor were 3 times higher risk for $[\mathrm{AOR}=3.5 \mathrm{CI}(1.5,9.4)]$ stillbirth than women who did not have obstructed labor. Moreover, the odds of a mother who had antepartum hemorrhages were 4 times at risk $[\mathrm{AOR}=4.3 \mathrm{CI}$ (2.1, 9.05)] for stillbirth than women who did not have antepartum hemorrhages. Finally, odds of women who had a diagnosis of congenital anomalies were 9 times at risk $[\mathrm{AOR}=9.7 \mathrm{CI}(4.08,23.0)]$ for stillbirth than women who did not have congenital anomalies (Table 4).

\section{Discussion}

This study showed that antenatal care visits, lack of partograph utilization and mode of delivery, duration of labor, antepartum hemorrhages, obstructed labor, and congenital anomalies were statistically associated with stillbirth.

The current study showed that odd of a mother who had four antenatal care visits were $62 \%$ less likely risk for stillbirth than odds of a mother who have less than four antenatal care visits. This finding was supported by a study conducted in southwest Ethiopia [18], a study in Kenya [20], a study in Nigeria [21], a study in Nepal [22] and study in Zimbabwe [23], a study in Tanzania [24]. The consistency of the finding might be due to methodological similarity between the studies, possibly could be explained antenatal care provide discussion time for women to understanding growth and the requirement of the development for their fetus and the support needed during pregnancy time as well as increase their awareness maintain adequate health. The systematic review revealed antenatal care helps to screen and early detection of pregnancy at risk $[4,25,26]$.

This present study also showed that mother her labor not followed by using partograph was 4 times higher at risk for stillbirth than labor followed by partograph. This finding was consistent with a study in Nigeria [21], in Uganda [27], in Nepal [22]. This consistency of the finding could be due to methodological relation between the study and could be explained if partograph not utilized obstructed labor, and prolonged labor which might be led to severe fetal compromise during the intrapartum period difficulty to diagnosis and thus maybe end in stillbirth. The existing evidence also supported that partograph utilization during labor followed and monitoring could be averted stillbirth in a facility where emergency obstetric care is available $[1,28]$.

This study finds that the odds of mothers gave birth by cesarean delivery was $67 \%$ less likely risk of developing stillbirth than odds of mothers gave birth through vaginal delivery.

The finding was consistent with the study in India [29], a study in Tanzania [24]. The comparability of the finding could be explained due to the cesarean section usually done electively based maternal request, in addition 
Table 2 Obstetrics and medical illness-related factors of the study participants of Hawassa University comprehensive Specialized Referral Hospital, Hawassa Sidama, 2019

\begin{tabular}{|c|c|c|c|c|}
\hline Variables & Category & $\begin{array}{l}\text { Cases } \\
\mathrm{N}(\%)\end{array}$ & $\begin{array}{l}\text { Controls } \\
\mathrm{N}(\%)\end{array}$ & $p$-value \\
\hline \multirow[t]{2}{*}{ Labor onset } & Spontaneous & $66(62.3)$ & $227(71.4)$ & 0.078 \\
\hline & Induced & $40(37.7)$ & 91 (28.6) & \\
\hline \multirow[t]{2}{*}{ Mode of delivery } & V/D & $73(68.9)$ & $156(49.1)$ & 0.003 \\
\hline & $\mathrm{C} / \mathrm{S}$ & $33(31.1)$ & $162(50.9)$ & \\
\hline \multirow[t]{2}{*}{ Length of labour } & $<24 \mathrm{~h}$ & $66(62.3)$ & $291(91.5)$ & 0.0001 \\
\hline & $>24 \mathrm{~h}$ & $40(37.7)$ & $27(8.5)$ & \\
\hline \multirow[t]{2}{*}{ Where at labor started } & At home & $57(53.8)$ & $230(72.3)$ & 0.0004 \\
\hline & At facility & $49(46.2)$ & 88 (27.7) & \\
\hline \multirow[t]{2}{*}{ Obstructed labour } & Yes & $24(22.6)$ & $34(10.7)$ & 0.002 \\
\hline & No & $82(77.4)$ & $284(89.3)$ & \\
\hline \multirow[t]{2}{*}{ Oligo-hydramnios } & Yes & $7(6.6)$ & $21(6.6)$ & 1.000 \\
\hline & No & 99 (93.4) & $297(93.4)$ & \\
\hline \multirow[t]{2}{*}{ Poly-hydramnios } & Yes & $4(3.8)$ & $5(1.6)$ & 0.173 \\
\hline & No & $102(96.2)$ & $313(98.4)$ & \\
\hline \multirow[t]{2}{*}{ multiple pregnancy } & Yes & $4(3.8)$ & $12(3.8)$ & 1.000 \\
\hline & No & $102(96.2)$ & $306(96.2)$ & \\
\hline \multirow[t]{2}{*}{$\mathrm{APH}$} & Yes & $40(37.7)$ & $56(17.6)$ & 0.0001 \\
\hline & No & $66(62.3)$ & $262(82.4)$ & \\
\hline \multirow[t]{2}{*}{ PROM } & Yes & $32(30.2)$ & $85(26.7)$ & 0.490 \\
\hline & No & $74(69.8)$ & $233(73.3)$ & \\
\hline \multirow[t]{2}{*}{ Chorioamnionitis } & Yes & $14(13.2)$ & $31(9.7)$ & 0.137 \\
\hline & No & $92(86.8)$ & $287(90.3)$ & \\
\hline \multirow[t]{2}{*}{ PIHTN } & Yes & $29(27.4)$ & $58(18.2)$ & 0.044 \\
\hline & No & 77 (72.6) & $260(81.8)$ & \\
\hline \multirow[t]{2}{*}{ Anemia } & Yes & $33(31.1)$ & $50(15.7)$ & 0.001 \\
\hline & No & $73(68.9)$ & $268(84.3)$ & \\
\hline \multirow[t]{2}{*}{ GDM } & Yes & $8(7.5)$ & $13(4.1)$ & 0.155 \\
\hline & No & $98(92.5)$ & 305 (95.9) & \\
\hline \multirow[t]{2}{*}{ HIV/AIDS } & $\mathrm{R}$ & $9(8.5)$ & 38 (11.9) & 0.326 \\
\hline & $N R$ & $97(91.5)$ & $280(88.1)$ & \\
\hline \multirow[t]{2}{*}{ Syphilis status } & Positive & $5(4.7)$ & $26(8.2)$ & 0.236 \\
\hline & Negative & $101(95.3)$ & $292(91.8)$ & \\
\hline \multirow[t]{2}{*}{ UTI } & Yes & $12(11.3)$ & $35(11.0)$ & 0.929 \\
\hline & No & $94(88.7)$ & $283(89.0)$ & \\
\hline \multirow[t]{2}{*}{ Malaria } & Yes & $4(3.8)$ & $16(5.0)$ & 0.597 \\
\hline & No & $102(96.2)$ & 302 (95.0) & \\
\hline
\end{tabular}

Notes: $A P H$ Antepartum hemorrhage, PROM (Premature rupture of membranes), PIHTN (pregnancy-induced hypertension), GHTN (Gestational hypertension, chronic hypertension) $N=$ number while (\%) represents percentages, GDM Gestational diabetes mellitus

to this the exiting data validate caesarian delivery often performed when a vaginal delivery would put a fetus at risk to minimize fetal loss [30]. However, a study
Table 3 Fetal related factors of study participants in Hawassa University comprehensive Specialized referral Hospital, Hawassa Sidama 2019

\begin{tabular}{lllll}
\hline Variables & Category & $\begin{array}{l}\text { Cases } \\
\text { N (\%) }\end{array}$ & $\begin{array}{l}\text { Controls } \\
\text { N (\%) }\end{array}$ & P-value \\
\hline Fetal status at admission & Normal & $38(35.8)$ & $224(70.4)$ & 0.0001 \\
& In distress & $68(64.2)$ & $94(29.6)$ & \\
Cord prolapsed & Yes & $10(9.4)$ & $9(2.8)$ & 0.004 \\
Congenital anomalies & No & $96(90.6)$ & $309(97.2)$ & \\
& Yes & $21(19.8)$ & $16(5.0)$ & 0.0003 \\
Gestational age & No & $85(80.2)$ & $302(95.0)$ & \\
& $<37$ weeks & $36(34.0)$ & $65(20.4)$ & 0.014 \\
Fetal birth weight & 37 to 42 & $51(48.1)$ & $195(61.3)$ & \\
& $>42$ weeks & $19(17.9)$ & $58(18.2)$ & \\
& LBW & $34(32.1)$ & $52(16.4)$ & 0.002 \\
Fetal presentation & NBW & $61(57.5)$ & $235(73.9)$ & \\
& Macrosomia & $11(10.4)$ & $31(9.7)$ & \\
Fetal sex & Cephalic & $73(68.9)$ & $203(63.8)$ & 0.347 \\
& Non-cephalic & $33(31.1)$ & $115(36.2)$ & \\
& Female & $59(55.7)$ & $188(59.1)$ & 0.532 \\
\hline
\end{tabular}

Notes: $N$ Number while, (\%) represents a percent. LBW Low birth weight, NBW Normal birth weight

conducted in Nepal showed that the mode of delivery not statistically associated with stillbirth [22].

This study also showed odd of women's diagnosis of prolonged labor was 6 times more at risk for stillbirth than odds of women gave birth within $24 \mathrm{~h}$ of the onset of labor. The finding was consistent with the study in Nigeria [31] and study in southwestern Ethiopia [18]. The possible consistency could be due to similarities of methodology between studies and prolonged labor could result in strenuous uterine contraction which maybe results in a non-reassurance fetal heart rate as well as increases the risk of stillbirth outcome. The systematic review and meta-analysis also showed prolonged labor end with stillbirth due to different obstetric difficulties if immediate intervention not undertaken [32, 33]. In a contrary study conducted in Uganda [27], the study in Nigeria [21] duration of labor not shown a statistical association with stillbirth.

In the current study women who had a diagnosis of obstructed labor were 3 times more at risk for stillbirth than women who did not have obstructed labor during labor and delivery. The finding was consistent with a study conducted in south Ethiopia [19] This possible explanation could be due to delay in visiting health facility or referral system, as well as failure to diagnosis and poor emergency preparedness, which results in rupture of the uterus, can be increase stillbirth. In a 
Table 4 logistic regression analysis of factors associated with stillbirth among women who gave birth in Hawassa University comprehensive Specialized referral Hospital, Hawassa, Sidma Ethiopia, 2019

\begin{tabular}{|c|c|c|c|c|c|}
\hline Variable & Category & $\begin{array}{l}\text { Case } \\
\text { N (\%) }\end{array}$ & $\begin{array}{l}\text { Control } \\
\mathrm{N}(\%)\end{array}$ & COR $95 \% \mathrm{Cl}$ & AOR $95 \% \mathrm{Cl}$ \\
\hline \multirow[t]{2}{*}{ Maternal residence } & Urban & $50(47.2)$ & $188(59.1)$ & 1 & 1 \\
\hline & Rural & $56(52.8)$ & $130(40.9)$ & $1.62(1.0,2.52)$ & $1.1(0.58,2.13)$ \\
\hline \multirow[t]{2}{*}{ Previous stillbirth } & Yes & $12(11.3)$ & $22(6.9)$ & $1.71(0.81,3.6)$ & $1.6(0.58,4.85)$ \\
\hline & No & $94(88.7)$ & $296(93.1)$ & 1 & 1 \\
\hline \multirow[t]{2}{*}{ ANC visit } & $1-3$ visit & 78 (87.6) & $196(74.2)$ & 1 & 1 \\
\hline & 4 visit & $11(12.4)$ & $68(25.8)$ & $0.40(0.20,0.81)$ & $0.38(0.15,0.95)^{*}$ \\
\hline \multirow[t]{2}{*}{ Partograph utilized } & Yes & $86(81.1)$ & $298(93.7)$ & 1 & 1 \\
\hline & No & $20(18.9)$ & $20(6.3)$ & $3.46(1.78,6.73)$ & $4.1(2.04,10.5)^{*}$ \\
\hline \multirow[t]{2}{*}{ Length of labour } & $<24$ & $66(62.3)$ & $291(91.5)$ & 1 & 1 \\
\hline & $>24$ & $40(37.7)$ & $27(8.5)$ & $6.5(3.7,11.3)$ & $6.5(2.9,14.4)^{* * *}$ \\
\hline \multirow[t]{2}{*}{ Mode of delivery } & $\mathrm{V} / \mathrm{D}$ & $73(68.9)$ & $156(49.1)$ & 1 & 1 \\
\hline & $\mathrm{C} / \mathrm{S}$ & $33(31.1)$ & $162(50.9)$ & $0.43(0.27,0.69)$ & $0.33(0.16,0.68)^{* *}$ \\
\hline \multirow[t]{2}{*}{ Antepartum hemorrhage } & Yes & $40(37.7)$ & $56(17.6)$ & $6.5(3.7,11.3)$ & $4.3(2.1,9.05)^{* * *}$ \\
\hline & No & $66(62.3)$ & $262(82.4)$ & 1 & 1 \\
\hline \multirow[t]{2}{*}{ Pregnancy induced hypertension } & Yes & $29(27.4)$ & $58(18.2)$ & $1.68(1.01,2.8)$ & $2.08(0.99,4.3)$ \\
\hline & No & $77(72.6)$ & $260(81.8)$ & 1 & 1 \\
\hline \multirow[t]{2}{*}{ Obstructed labour } & Yes & $24(22.6)$ & $34(10.7)$ & $2.44(1.37,4.35)$ & $3.5(1.5,9.4)^{* *}$ \\
\hline & No & $82(77.4)$ & $284(89.3)$ & 1 & 1 \\
\hline \multirow[t]{2}{*}{ Gestational Diabetes Miletus } & Yes & $8(7.5)$ & $13(4.1)$ & $1.91(0.77,4.75)$ & $2.29(0.58,8.9)$ \\
\hline & No & $98(92.5)$ & $305(95.9)$ & 1 & 1 \\
\hline \multirow[t]{2}{*}{ Anemia } & Yes & $33(31.1)$ & $50(15.7)$ & $2.42(1.45,4.03)$ & $1.6(0.79,3.4)$ \\
\hline & No & $73(68.9)$ & $268(84.3)$ & 1 & 1 \\
\hline \multirow[t]{2}{*}{ Congenital anomalies } & Yes & $21(19.8)$ & $16(5.0)$ & $4.66(2.3,9.3)$ & $9.7(4.08,23.0) * * *$ \\
\hline & No & $85(80.2)$ & $302(95.0)$ & 1 & 1 \\
\hline \multirow[t]{3}{*}{ Gestational age } & Preterm & $36(34.0)$ & $65(20.4)$ & 1 & 1 \\
\hline & Term & $51(48.1)$ & $195(61.3)$ & $0.47(0.28,0.78)$ & $0.90(0.35,2.29)$ \\
\hline & Post term & $19(17.9)$ & $58(18.2)$ & $0.59(0.30,1.14)$ & $0.75(0.24,2.3)$ \\
\hline \multirow[t]{3}{*}{ Fetal weight } & LBW & $34(32.1)$ & $52(16.4)$ & 1 & 1 \\
\hline & NBW & $61(57.5)$ & 235 (73.9) & $0.39(0.23,0.66)$ & $0.53(0.21,1.31)$ \\
\hline & Macrosomia & $11(10.4)$ & $31(9.7)$ & $0.54(0.24,1.22)$ & $0.54(0.11,2.6)$ \\
\hline
\end{tabular}

Key: reference category $=1: P$-value significant at: ${ }^{*} p<0.05,{ }^{* *} p<0.01,{ }^{* * *} p<0.001, N$ Number while (\%) represents percentages

contrary study in south-west Ethiopia [18] obstructed labor shown no statistical association with stillbirth.

Odd of who had a diagnosis of Antepartum hemorrhage was 4 times more at risk for stillbirth than odds of who women do not have antepartum hemorrhages. This finding was consistent with a study in Nigeria [21], in Zimbabwe [23], and south Ethiopia [18, 19]. The consistency of the findings could be due to methodological similarity of the study, the possible explanation can be some obstetrics causes of antepartum hemorrhage results in excess bleeding which maybe leads anemia and decreased placental perfusion as well as fetal hypoxia that increases the risk of stillbirth. This was confirmed by the available evidence [34].

This study finds the odd women gave fetal congenital anomaly was 9 times at risk for stillbirth than odd women gave fetally had no congenital anomalies. The finding was consistent with a study in Nigeria countries $[20,24]$. The possible explanation could be due to methodological familiarity, study population, and the possible explanation could be screening during the antenatal period due to limited advanced diagnostic procedures and related with a skill for prenatal autopsy in developing countries. The systematic review and 
meta-analysis also reveal that major types of congenital anomaly were incompatible with life $[25,35,36]$. Inconsistently a study conducted in Srilanka [37] (Samaraweera 2019) and Tanzania [24] showed that congenital anomaly no statistical association with stillbirth.

The study reviews multiple exposures for stillbirth as well as both cases and controls were selected from the same setting and population this may reduce selection bias between cases and controls. This study was used secondary data as a source of information, there might be intra-observer bias and diagnosis as well as missing a variable during data collection.

\section{Conclusion}

This study identified antenatal care and caesarian delivery was Negatively associated with stillbirth. Whereas not using partograph, prolonged labor, antepartum hemorrhages, obstructed labor, and congenital anomaly were positively associated with stillbirth. The current study indicated that National policy, structural, and process play a significant role in the quality of service provision. The government plays a role with respective stakeholders to decrease drop out of ANC visits and facilities must give orientation for their providers about respectful and compassionate care and the quality department of respective units must follow the providers during the intrapartum period to follow women with partograph. The study strongly recommended future researchers to do an interventional study that could be addressed preconception care utilization because in current study congenital anomaly the strongest factor associated with stillbirth.

\section{Abbreviations}

APH: Antepartum Hemorrhage; ANC: Antenatal Care; AOR: Adjusted Odd Ratio; WHO: World Health Organization

\section{Acknowledgments}

We wish to express our sincere gratitude to Hawassa University College of medicine and health sciences for financial support.

\section{Authors' contributions}

SE took part in designing the study, conducted, took part in the full parts of articles, extracted and analyzed the data; write the initial draft of the paper. RF and TG supervise the idea and took part in follow up the principal investigators, oversaw its conduct and analysis, and contributed to the initial and final drafts of the paper and AA participate in manuscript preparation and editing. The authors read and approved the final manuscript.

\section{Funding}

This study was conducted under the Ministry of Science and Higher Education and supervision of Hawassa University College of Medicine and Health Sciences.

\section{Availability of data and materials}

If you request, we can avail all the data used.

\section{Ethics approval and consent to participate}

The letter of ethical clearance received from the Institutional Review Board of Hawassa University in the Reference number of 212/11, while permission letter obtained from the clinical director office of Hawassa University
Comprehensive Specialized Hospital for getting necessary information concerning the individual maternal medical record charts.

Consent for publication

Not applicable.

\section{Competing interests}

The authors declare no competing interest.

\section{Author details}

${ }^{1}$ Mettu University, College of Health Science, P.O. Box 2156, Mettu, Ethiopia. ${ }^{2}$ Hawassa University, College of Medicine and Health Science, School of public health, P.O. Box 1560, Awassa, Ethiopia.

Received: 9 October 2020 Accepted: 14 January 2021

Published online: 17 February 2021

\section{References}

1. WHO. "The WHO application of ICD-10 to deaths during the perinatal period: ICD-PM." WHO library cataloguing-in-publication data (prenatal death ), vol. 88; 2016

2. WHO. Pregnancy, childbirth, postpartum and newborn care, a guide for essential practice, World Health Organization; 2006.

3. Organization, W. H. and UNICEF. Reaching the every newborn national 2020 milestones: country progress, plans and moving forward; 2017.

4. Beauclair R, Petro G, Myer $L$. The association between timing of initiation of antenatal care and stillbirths: a retrospective cohort study of pregnant women in Cape Town, South Africa. BMC Pregnancy Childbirth. 2014;14(1):204.

5. Lawn JE, Blencowe H, Waiswa P, Amouzou A, Mathers C, Hogan D. Stillbirths: rates, risk factors, and acceleration towards 2030. Lancet. 2016;387:1.

6. Blencowe H, Cousens S, Jassir FB, Say L, Chou D, Mathers C, et al. National, regional, and worldwide estimates of stillbirth rates in 2015, with trends from 2000: a systematic analysis. Lancet Glob Health. 2016;4(2):e98-e108.

7. Cousens S, Blencowe H, Stanton C, Chou D, Ahmed S, Steinhardt L, et al. National, regional, and worldwide estimates of stillbirth rates in 2009 with trends since 1995: a systematic analysis. Lancet. 2011;377(9774):1319-30.

8. Frøen JF, Cacciatore J, McClure EM, Kuti O, Jokhio AH, Islam M, et al. Stillbirths: why they matter. Lancet. 2011;377(9774):1353-66.

9. Izutsu T, Tsutsumi A, Minas $H$, Thornicroft G, Patel V, Ito A. Mental health and wellbeing in the sustainable development goals. Lancet Psychiatry. 2015:2(12):1052-4.

10. Alkema L, Chou D, Hogan D, Zhang S, Moller A-B, Gemmill A, et al. Global, regional, and national levels and trends in maternal mortality between 1990 and 2015, with scenario-based projections to 2030: a systematic analysis by the UN maternal mortality estimation inter-agency group. Lancet. 2016; 387(10017):462-74.

11. Sather M, Fajon A-V, Zaentz R, Rubens CE. Global report on preterm birth and stillbirth (5 of 7): advocacy barriers and opportunities. BMC Pregnancy Childbirth. 2010;10(1):S5.

12. Mullan Z, Horton R. Bringing stillbirths out of the shadows. Lancet. 2011; 377(9774):1291-2

13. Boyle FM. Mothers bereaved by stillbirth, neonatal death or sudden infant death syndrome: patterns of distress and recovery: Routledge; 2018.

14. Lawn JE, Blencowe H, Pattinson R, Cousens S, Kumar R, Ibiebele I, et al. Stillbirths: where? When? Why? How to make the data count? Lancet. 2011; 377(9775):1448-63.

15. Lamont K, Scott NW, Jones GT, Bhattacharya S. Risk of recurrent stillbirth: systematic review and meta-analysis. Br Med J. 2015;350:h3080.

16. McKinnon B, Harper S, Kaufman JS, Bergevin Y. Socioeconomic inequality in neonatal mortality in countries of low and middle income: a multicountry analysis. Lancet Glob Health. 2014;2(3):e165-73.

17. EDHS. Ethiopia demographic and health survey 2016. Addis Ababa and Rockville: CSA and ICF; 2016.

18. Welegebriel TK, Dadi TL, Mihrete KM. Determinants of stillbirth in Bonga general and Mizan Tepi University teaching hospitals southwestern Ethiopia, 2016: a case-control study. BMC Res Notes. 2017;10(1):713.

19. Bayou G, Berhan Y. Perinatal mortality and associated risk factors: a case control study. Ethiop J Health Sci. 2012;22(3):153-62. 
20. Yego F, D'Este C, Byles J, Nyongesa P, Williams JS. A case-control study of risk factors for fetal and early neonatal deaths in a tertiary hospital in Kenya. BMC Pregnancy Childbirth. 2014;14(1):389.

21. Suleiman BM, Ibrahim $H$, Abdulkarim N. Determinants of stillbirths in Katsina, Nigeria: a hospital-based study. Pediatr Rep. 2015;7(1):1.

22. Ashish K, Wrammert J, Ewald U, Clark RB, Gautam J, Baral G, et al. Incidence of intrapartum stillbirth and associated risk factors in tertiary care setting of Nepal: a case-control study. Reprod Health. 2016;13(1):103.

23. Tachiweyika E, Gombe N, Shambira G, Chadambuka A, Tshimamga M, Zizhou S. Determinants of perinatal mortality in Marondera district, Mashonaland East Province of Zimbabwe, 2009: a case control study. Pan African Med J. 2011;8(1):1.

24. Chuwa FS, Mwanamsangu AH, Brown BG, Msuya SE, Senkoro EE, Mnali OP, et al. Maternal and fetal risk factors for stillbirth in northern Tanzania: a registry-based retrospective cohort study. PLoS One. 2017:12(8):e0182250.

25. McClure EM, Saleem S, Goudar SS, Moore JL, Garces A, Esamai F. Stillbirth rates in low-middle income countries 2010-2013: a population-based, multicountry study from the global network. Reprod Health. 2015;12:1.

26. McClure EM, Saleem S, Pasha O, Goldenberg RL. Stillbirth in developing countries: a review of causes, risk factors and prevention strategies. J Matern Fetal Neonatal Med. 2009;22:1.

27. Agaba E. Factors associated with stillbirths at Mbarara regional referral hospital. Int Peer-Rev J. 2016;24:2016 ISSN 2422-8419.

28. Yisma E, Dessalegn B, Astatkie A, Fesseha N, et al. Knwoledge and utilization of partograph among obstetrics care givers in public institutions of Addis Ababa, Ethiopia. BMC Pregnancy Childbirth. 2013;13:17.

29. Newtonraj A, Kaur M, Gupta M, Kumar R. Level, causes, and risk factors of stillbirth: a population-based case control study from Chandigarh, India. BMC Pregnancy Childbirth. 2017;17(1):371.

30. Betrán AP, Torloni MR, Zhang J-J, Gülmezoglu A. WHO statement on caesarean section rates. BJOG Int J Obstet Gynaecol. 2016;123(5):667-70.

31. Alkali YS, Jalo I, AU EN, Bode-Thomas F. Causes of stillbirth in a community survey in Gombe state. Niger J Paed. 2014;41:1.

32. Nahar S, Rahman A, Nasreen HE. Factors influencing stillbirth in B angladesh: a case-control study. Paediatr Perinat Epidemiol. 2013;27(2):158-64.

33. Geelhoed D, StokX J, Mariano X, Lázaro CM, Roelens K. Risk factors for stillbirths in Tete, Mozambique. Int J Gynecol Obstet. 2015;130(2):148-52

34. Smith GC, Fretts RC. Stillbirth. Lancet. 2007;370(9600):1715-25.

35. Flenady V, Koopmans L, Middleton P, Frøen JF, Smith GC, Gibbons K. Major risk factors for stillbirth in high-income countries: a systematic review and meta-analysis. Lancet. 2011;377:1331.

36. Aminu M, Unkels R, Mdegela M, Utz B, Adaji S, Van Den Broek N. Causes of and factors associated with stillbirth in low-and middle-income countries: a systematic literature review. BJOG Int J Obstet Gynaecol. 2014;121:141-53.

37. Samaraweera D. Effects of selected socio-demographic, maternal, service-related and psychological risk factors for still births delivered in district general hospital, Matara, Sri Lanka during 2015-2018; 2019 Open Access Journal

\section{Publisher's Note}

Springer Nature remains neutral with regard to jurisdictional claims in published maps and institutional affiliations.

Ready to submit your research? Choose BMC and benefit from:

- fast, convenient online submission

- thorough peer review by experienced researchers in your field

- rapid publication on acceptance

- support for research data, including large and complex data types

- gold Open Access which fosters wider collaboration and increased citations

- maximum visibility for your research: over $100 \mathrm{M}$ website views per year

At $\mathrm{BMC}$, research is always in progress.

Learn more biomedcentral.com/submissions 